\title{
Hepatitis B virus $X$ protein activates human hepatic stellate cells through upregulating TGFß1
}

\author{
H.-Y. Chen, Z.-X. Chen, R.-F. Huang, N. Lin and X.-Z. Wang \\ Department of Gastroenterology, Union Hospital of Fujian Medical University, \\ Fuzhou, China \\ Corresponding author: X.-Z. Wang \\ E-mail: drwangxz@163.com
}

Genet. Mol. Res. 13 (4): 8645-8656 (2014)

Received April 17, 2013

Accepted October 2, 2013

Published October 27, 2014

DOI http://dx.doi.org/10.4238/2014.October.27.4

\begin{abstract}
We investigated the effects of the hepatitis B virus X gene $(H B V X)$ on the activation of human hepatic stellate cells (HSCs) and the possible mechanisms underlying the pathway. Recombinant plasmid pHBV-X-IRES2-EGFP was constructed and transfected into HL-7702 cells using a lipid-mediated method. Transfected cells were screened by G418, which detected stable expression of the $\mathrm{X}$ gene by reverse transcription (RT)-PCR and Western blot analysis, and named L02/x. Cells not subjected to G418-selection were analyzed to confirm the transient expression of the X gene and named L02/48x. Subsequently, L02/x and L02/48x, together with non-HBx-expressing cells, were cocultured with HSCs in a non-contact transwell system. After $36 \mathrm{~h}$ of co-culture, the proliferation and migration of HSCs was detected using different cell counting methods. Finally, the mRNA and protein levels of $\alpha-S M A, C o l$ I, and TGF $\beta 1$ in HSCs were detected by real-time PCR and western blot analysis. RT-PCR and Western blot analysis showed that L02/x and L02/48x cells can express $H B V X$ gene mRNA and protein. Additionally, HSCs co-cultured with L02/x or L02/48x cells showed significantly higher proliferation and migration levels than
\end{abstract}


control groups. Real-time PCR and Western blot analysis showed that the mRNA and protein expressions of $\alpha-S M A, \operatorname{Col} I$, and TGF $\beta 1$ in HSCs co-cultured with HBx-expressing liver cells were higher than those in control groups. HBx protein activated HSCs in vitro, leading to increased proliferation and migration of HSCs and upregulation of $\alpha-S M A$ and $C o l$ I. The TGF $\beta 1$ gene may be involved in this pathway.

Keywords: Hepatitis B virus $\mathrm{X}(H B V X)$ gene; Gene activation; TGF $\beta 1$; Hepatic stellate cells (HSC); Co-culture system

\section{INTRODUCTION}

Chronic hepatitis B virus (HBV) infection has been identified as a major risk factor in the development of cirrhosis and hepatocellular carcinoma (HCC), affecting more than 350 million people worldwide (Nebbia et al., 2012). The HBV X protein (HBx) is encoded by the $H B V X$ gene, which is the smallest open reading frame of the $H B V$ gene and is thought to play important roles in HBV-associated HCC by affecting gene transcription (Dewantoro et al., 2006; Matsuda and Ichida, 2009; Yip et al., 2011), DNA repair (Chen et al., 2008; Kim et al., 2010; Qadri et al., 2011), intracellular signal transduction (Chen et al., 2004; Ha and Yu, 2010; Hsieh et al., 2011), apoptosis (Gearhart and Bouchard, 2011; Knoll et al., 2011), and the cell cycle (Chen et al., 2008; Martín-Lluesma et al., 2008; Gearhart and Bouchard, 2011).

Recently, several studies have shown that HBx may be linked to HBV-induced fibrosis progression. Martín-Vílchez et al. (2008) showed that HBx protein induced paracrine activation of hepatic stellate cells (HSCs) in vitro and played a direct role in the development of liver fibrosis. Guo et al. (2009) found that HBx may facilitate liver fibrosis by promoting HSC proliferation. Additionally, these studies both revealed that the $T G F \beta$ gene may be involved in this pathway (Martín-Vílchez et al., 2008; Guo et al., 2009). However, the exact roles of the HBx protein in cirrhosis remain largely unknown and the molecular mechanisms of HBVlinked fibrosis remain unclear.

To explore the effects of the HBx protein on the development of HBV-associated cirrhosis, we constructed HL-7702 cells expressing the $H B V X$ gene steadily or transiently. Additionally, HBx-carrying cells were co-cultured with HSCs in transwell systems to analyze the effect of HBx on HSC activation. Next, the expression of genes potentially related to these processes was detected to understand the mechanisms of HBx-associated fibrosis.

\section{MATERIAL AND METHODS}

\section{Construction of $H B V X$-expressing vector}

The HBV X DNA fragment was amplified by polymerase chain reaction (PCR) using the middle vector PUCmT-X, which was reserved by our laboratory as a template. The sequences of primers used for PCR were as follows: 5'-TAATCTCGAGATGGCTGCTAGGCTGTGCT-3' and 5'-GTCAGAATTCTTAATGGTGATGGTGATGATGGGCAGAGGTGAAAAAGTTGC-3'. PCR was carried out as follows: pre-denaturation at $94^{\circ} \mathrm{C}$ for 30 min and 35 amplification cycles (denaturation at $94^{\circ} \mathrm{C}$ for $30 \mathrm{~s}$, annealing at $57^{\circ} \mathrm{C}$ for $30 \mathrm{~s}$, and extension at $68^{\circ} \mathrm{C}$ for 
30 s). Next, PCR products were digested by $X h o \mathrm{I}$ and EcoRI and ligated into $p I R E S 2-E G F P$ to construct the reconstituted plasmid $p H B V$-X-IRES2-EGFP. Its sequence was confirmed by restriction endonuclease digestion and direct DNA sequencing.

\section{Cell culture and DNA transfection}

HL-7702 cells were purchased from the Institute of Biochemistry and Cell Biology (Shanghai, China) and cultured in DMEM supplemented with $10 \%$ fetal bovine serum. Cells in the logarithmic growth were separately transfected with $p H B V-X-I R E S 2-E G F P$ and pIRES2-EGFP plasmids using Lipo2000 transfection reagent, which was obtained from Invitrogen (Carlsbad, CA, USA). After $48 \mathrm{~h}$, transfected cells were observed using a fluorescence microscope to evaluate transfection efficiency and the cells were divided into 2 groups. One group was selected using G418. After 2 weeks of selection, positive clones were isolated and further expanded, and these clones were referred to as L02/x and L02/ctr. Another group of cells was transfected transiently for $48 \mathrm{~h}$ without G418 selection and separately referred to as L02/48x and L02/48ctr. Corresponding control groups without transfection were referred to as $\mathrm{L} 02 / \mathrm{NC}$ and $\mathrm{L} 02 / 48 \mathrm{NC}$, respectively.

\section{RT-PCR}

RNA from the 3 groups of cells (L02/x, L02/48x, and HL-7702) were extracted separately and reverse transcribed into cDNA according to manufacturer instructions of the MMLV reverse transcription kits, which were purchased from Promega (Madison, WI, USA). Using 2 $\mathrm{mL}$ RT products as the template, the $X$ gene was amplified by PCR as follows: predenaturation for $2 \mathrm{~min}$ at $95^{\circ} \mathrm{C}$ and 40 amplification cycles (denaturation at $95^{\circ} \mathrm{C}$ for $20 \mathrm{~s}$, annealing at $57^{\circ} \mathrm{C}$ for $15 \mathrm{~s}$, and extension at $72^{\circ} \mathrm{C}$ for $20 \mathrm{~s}$ ). Primers used to amplify the $X$ gene and the control gene $h A C T B$ are shown in Table 1.

Table 1. RT-PCR primers of the $H B V X$ gene and control gene $h A C T B$.

\begin{tabular}{llc}
\hline Primer & Sequence & Product $(\mathrm{bp})$ \\
\hline$H B V X-F 1$ & CCCGTCTGTGCCTTCTCATC & 105 \\
$H B V X-R l$ & ATCTCCTCCCCCAACTCCTC & \\
$H B V X-12$ & CTAGGCTGTGCTGCCAACTG & 182 \\
$H B V X-R 2$ & AGAAGGCACAGACGGGGAGT & 208 \\
$h A C T B-F$ & TCCTTCCTGGGCATGGAGT & 208 \\
$h A C T B-R$ & CAGGAGGAGCAATGATCTTGAT & \\
\hline
\end{tabular}

\section{Western blot}

$\mathrm{L} 02 / \mathrm{x}, \mathrm{L} 02 / \mathrm{ctr}, \mathrm{L} 02 / \mathrm{NC}, \mathrm{L} 02 / 48 \mathrm{x}, \mathrm{L} 02 / 48 \mathrm{ctr}$, and L02/48NC cells were lysed in lysis buffer containing $50 \mathrm{mM}$ Tris-HCL, pH $8.5,150 \mathrm{mM} \mathrm{NaCl}, 0.2 \mathrm{~g} / \mathrm{L} \mathrm{NaN}_{3}, 0.1 \mathrm{~g} / \mathrm{L}$ sodium dodecyl sulfate (SDS), $100 \mathrm{mg} / \mathrm{mL}$ phenylmethylsulfonyl fluoride, $1 \mathrm{mg} / \mathrm{mL}$ aprotinin, 10 $\mathrm{mL} / \mathrm{L} \mathrm{NP}-40$, and $5 \mathrm{~g} / \mathrm{L}$ sodium deoxycholate. The products were centrifuged at $14,000 \mathrm{~g}$ for 15 min to remove cellular debris. Protein concentrations were determined by BCA methods according to the instructions of BCA protein assay kits. Equal amounts of each sample (50 $\mu \mathrm{g})$ were subjected to $12 \%$ SDS-polyacrylamide gel electrophoresis (PAGE) and then transferred 
to a polyvinylidene difluoride (PVDF) membrane. The membrane was blocked in TBST (10 $\mathrm{mM}$ Tris-Cl, $\mathrm{pH} 7.4,150 \mathrm{mM} \mathrm{NaCl}$, and $10 \mathrm{~mL} / \mathrm{L}$ Tween 20) containing $5 \%$ fat-free milk for 1 $\mathrm{h}$ and incubated overnight with the anti-HBx antibody (1:1000 dilution), which was obtained from Abcam (Cambridge, UK). The membrane was then washed 3 times for $15 \mathrm{~min}$ in TBST and incubated with anti-mouse immunoglobulin G for HBx. After washing, the bands were visualized by exposure to film with an ECL Western blot system from Zhongshan Biotechnology (Beijing, China).

\section{Construction of a co-culture system}

In a non-contact transwell co-culture system which was obtained from Corning Inc. (Corning, NY, USA), HSCs were cultured in the upper dishes, and 6 groups of live cells were separately cultured in the lower dishes in DMEM supplemented with $10 \%$ fetal bovine serum and 1\% Glutamax. Next, HSCs co-cultured with L02/x, L02/ctr, L02/NC, L02/48x, $\mathrm{L} 02 / 48 \mathrm{ctr}$, or $\mathrm{L} 02 / 48 \mathrm{NC}$ were referred to as $\mathrm{HSC} / \mathrm{x}, \mathrm{HSC} / \mathrm{ctr}, \mathrm{HSC} / \mathrm{NC}, \mathrm{HSC} / 48 \mathrm{x}, \mathrm{HSC} / 48 \mathrm{ctr}$, or $\mathrm{HSC} / 48 \mathrm{NC}$, respectively.

\section{Proliferation of HSCs}

After $36 \mathrm{~h}$ of co-culture, Cell Counting Kit (CCK)-8 reagents were added to the upper dishes about $10 \mu \mathrm{L}$ per dish. Absorbance values at $450 \mathrm{~nm}$ were measured after $3 \mathrm{~h}$. The absorbance value of the sample minus the value of blank was considered to be the final value. Each group was analyzed in triplicate.

\section{Migration of HSCs}

After $36 \mathrm{~h}$ of co-culture, moist swabs were used to erase the upper HSCs in the dishes. Next, the remaining cells were fixed with $4 \%$ paraformaldehyde for 15 min and dyed using crystal violet according to manufacturer instructions of crystal violet staining kits. The HSC migration was counted by measuring the absorbance at $570 \mathrm{~nm}$ using an absorbance microplate reader. Each sample was measured in triplicate.

\section{Real-time PCR}

The RNA from the 6 groups of co-cultured HSCs was extracted and reverse transcribed into cDNA. PCR primers for alpha-smoth muscle actin ( $\alpha-S M A)$, type 1 collagen $(\mathrm{Col}$ $I$ ), and the control gene $h A C T B$ were synthesized according to their corresponding sequences (Table 2). The best annealing temperatures and amount of templates were confirmed by RTPCR analysis. Real-time PCR was performed on a Mastercycler ep realplex PCR system (Eppendorf, Hamburg, Germany). The cDNA of each sample $(1 \mu \mathrm{L})$ was amplified in a $20-\mu \mathrm{L}$ reaction system containing $10 \mu \mathrm{L} 2 \mathrm{X}$ SYBR Green Mix, and $1 \mu \mathrm{L}$ primer mix. PCR conditions were as follows: predenaturation for $2 \mathrm{~min}$ at $95^{\circ} \mathrm{C}$, followed by 40 cycles at $95^{\circ} \mathrm{C}$ for $15 \mathrm{~s}, 44-$ $68^{\circ} \mathrm{C}$ for $30 \mathrm{~s}$, and $68^{\circ} \mathrm{C}$ for $60 \mathrm{~s}$. Data were collected and melting curves were analyzed. The relative expression level of each sample was calculated by comparing $\mathrm{CT}$ values with control groups. Each sample was run 3 times for each target gene. 
Table 2. Real-time PCR primers of $\alpha-S M A$, Col I, TGF $\beta 1$, and control gene $h A C T B$.

\begin{tabular}{llc}
\hline Primer & Sequence & Product (bp) \\
\hline$\alpha-S M A-F$ & GATGCTCCCAGGGCTGTTTT & 161 \\
$\alpha-S M A-R$ & TTGGTGATGATGCCATGTTCTAT & \\
COL $1 A 1-F 2$ & GCCTCCCAGAACATCACCTAC & 166 \\
$C O L 1 A 1-R 2$ & TCGTGCAGCCATCGACAGT & 197 \\
$T G F B 1-F$ & ACGAAATCTATGACAAGTTCAAGCA & \\
$T G F B 1-R$ & GCTGAGGTATCGCCAGGAAT & 208 \\
$h A C T B-F$ & TCCTTCCTGGGCATGGAGT & \\
$h A C T B-R$ & CAGGAGGAGCAATGATCTTGAT & \\
\hline
\end{tabular}

\section{Western blot}

The processes were similar to those described above. Briefly, protein products were extracted from the 4 groups of HSCs, including HSC/x, HSC/ctr, HSC/NC, and HSCs without co-culture. Next, $50 \mu \mathrm{g}$ samples were subjected to $10 \%$ SDS-PAGE and transferred to PVDF membranes. The membranes were blocked in 5\% fat-free milk in TBST and incubated with the primary antibody against either $\alpha$-SMA (1:1000 dilution), Col I (1:1000 dilution), or $\beta$-actin (1:4000 dilution) overnight at $4{ }^{\circ} \mathrm{C} . \alpha-S M A$ antibody was purchased from Abcam (Cambridge, UK). Col I alpha 1 (COL1A1) and $\beta$-actin antibodies were reserved by our laboratory. The membranes were then washed and incubated with the corresponding secondary antibodies. After washing, the bands were visualized by exposure to film with an ECL system. Each sample was run 3 times for each target gene.

\section{RNA and protein expression of TGF $\beta 1$}

Real-time PCR and Western blot analysis were used to detect the RNA and protein levels of TGF $\beta 1$. These procedures were similar to those described above. The primers required for real-time PCR are also described in Table 2 . The primary antibody for TGF $\beta 1$ in Western blot was from our laboratory and diluted to 1:100.

\section{Statistical analysis}

Data are reported as means \pm SD and statistical analysis was performed with independent samples $t$-test using the SPSS 17 software (SPSS, Chicago, IL, USA). P values $<0.05$ were considered to be statistically significant.

\section{RESULTS}

\section{Construction of $H B V X$ recombinant vector}

A 465-bp $H B V X$ gene fragment was amplified from $P U C m T-X$ and sub-cloned into the expression vector $p I R E S 2-E G F P$ to construct the recombinant vector $p H B V$-X-IRES2$E G F P$. The sequence of the $X$ gene in the plasmid was coincident with that reported previously as identified by restriction endoenzyme digestion (Figure 1) and confirmed by DNA direct sequencing (Figure 2). 


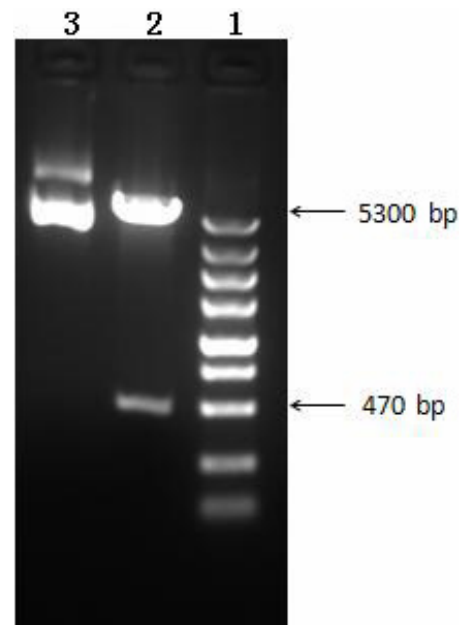

Figure 1. Restriction endonucleases digestion analysis of the recombinant plasmid. The recombinant vector $p H B V$ $X$-IRES2-EGFP was digested by $X h o \mathrm{I}$ and $B a m \mathrm{H} 1$ and electropheresed on a $1.5 \%$ agorose gel. A DNA fragment $(X$ gene) of $470 \mathrm{bp}$ was found in the digestion products of $p H B V-X-I R E S 2-E G F P$, but not in the recombinant vector without digestion. It means that the recombinant plasmid of $H B V X$ gene was constructed successfully. Lane $1=$ 5000-bp DNA ladder; lane 2 = restriction endonuclease digestion products of $p H B V$-X-IRES2-EGFP; lane $3=$ $p H B V-X$-IRES2-EGFP without digestion.

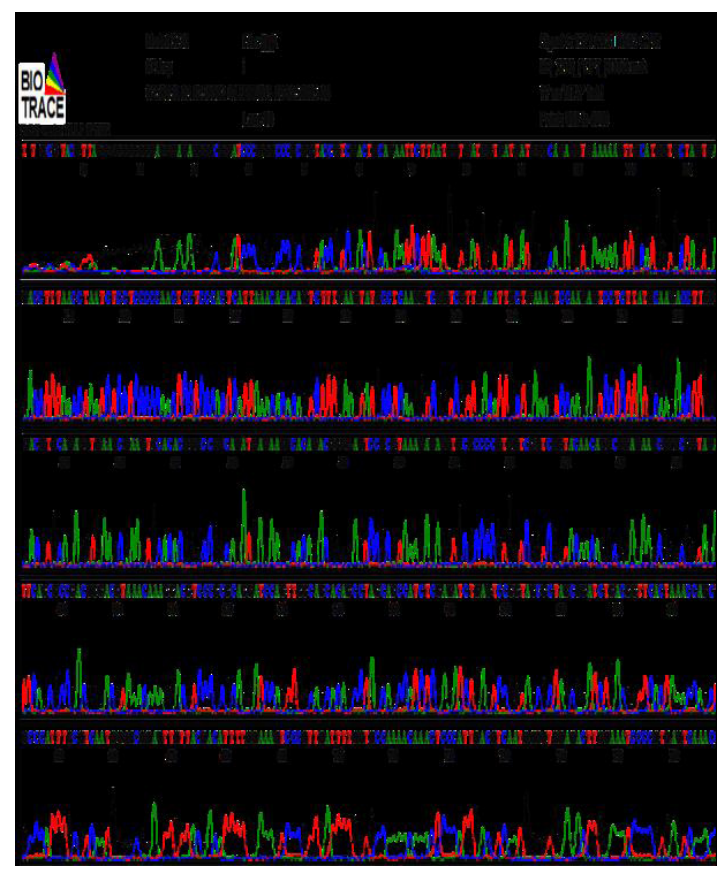

Figure 2. Sequencing result of the recombinant plasmid $p H B V-X-I R E S 2-E G F P$. The DNA sequence of $p H B V-X$ IRES2-EGFP was detected and compared with the $H B V X$ gene through NCBI online. A similarity of $99 \%$ was found between them. The result indicated that the $H B V X$ gene-expressing vector was constructed successfully. 


\section{Expression of the $H B x$ gene}

The $p H B V$-X-IRES2-EGFP and PIRES2-EGFP plasmids were transfected into HL7702 cells. After 48 h, cells were divided into 2 groups. One group was selected by G418 for 2 weeks and named L02/x and L02/ctr, respectively. Another group of cells without G418selection were named L02/48x and L02/48ctr, respectively. Non-transfected HL-7702 cells, as blank controls, were named L02/NC and L02/48NC. RT-PCR analysis showed that $H B V$ $X$ mRNA was detected in L02/x and L02/48x, but not in HL-7702 (Figure 3A). Western blot analysis showed protein expression of the $H B V X$ gene in L02/x and L02/48x, but not in L02/ ctr, L02/NC, L02/48ctr, or L02/48NC (Figure 3B). Thus, HBV X mRNA and protein were expressed steadily and transiently in L02/x and L02/48x, respectively.
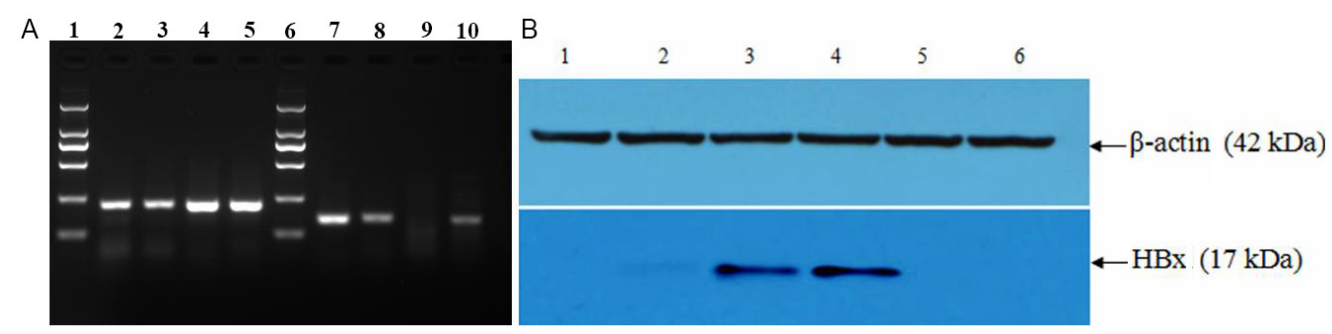

Figure 3. Expression of the $H B x$ A. Expressions of $H B V X$ mRNA in L02/x and L02/48x. RT-PCR analysis showed that $H B V X$ mRNA was detected in HL-7702 cells carrying the $X$ gene (L02/x and L02/48x), but not in HL-7702 cells without transfection. The result revealed that live cells expressing $H B V X$ mRNA steadily and transiently had been constructed. Lanes 1 and $6=2000$-bp DNA ladder; lanes 2-5 mRNA expressions of control gene $h A C T B$ in recombinant plasmid $p H B V$-X-IRES2-EGFP, L02/48x, HL-7702, and L02/x; lanes 7-10 = mRNA expressions of the $H B V X$ gene in $p H B V-X-I R E S 2-E G F P$, L02/48x, HL-7702, and L02/x. B. Expressions of HBx protein in L02/x and L02/48x. Western blot analysis showed that HBx protein $(17 \mathrm{kDa})$ was detected in HL-7702 cells carrying the $X$ gene (L02/x and L02/48x), but not in control groups (L02/ctr, L02/NC, L02/48ctr, and L02/48NC). The result revealed that live cells expressing HBx protein had been constructed. Lanes 1-3= protein expressions of the $H B V$ $X$ gene and the control gene $\beta$-actin in stable transfection group (L02/NC, L02/ctr and L02/x); lanes 4-6 = protein expressions of the $H B V X$ gene and the control gene $\beta$-actin in transient transfection group (L02/48x, L02/48ctr, and $\mathrm{L} 02 / 48 \mathrm{NC})$.

\section{Proliferation and migration of co-cultured HSCs}

HSCs were then separately co-cultured with L02/x, L02/ctr, L02/NC, L02/48x, L02/48ctr, and L02/48NC. CCK 8 kits were used to detect the proliferation of HSCs. The results showed that $\mathrm{HSC} / \mathrm{x}$ or $\mathrm{HSC} / 48 \mathrm{x}$ cells have significantly higher proliferation levels than the corresponding control groups (Figure 4A). Migration of HSCs was analyzed by crystal violet staining and $\mathrm{OD}_{570}$ detection. Statistical analysis showed that HSCs co-cultured with HBx-expressing live cells have significantly higher migration levels than the corresponding control groups (Figure 4B).

\section{Expression of $\alpha-S M A, C o l$, and TGFß1}

Real-time PCR revealed that the mRNA expression levels of $\alpha$-SMA, Col I, and 
$T G F \beta 1$ in the $\mathrm{HSC} / \mathrm{x}$ and $\mathrm{HSC} / 48 \mathrm{x}$ were all significantly higher than those in the corresponding control groups (Figure 5A,B,C; $\mathrm{P}<0.05$ ). Thus, the expression of the $H B V X$ gene in HL-7702 cells promoted mRNA expression of $\alpha$-SMA, Col I, and TGF $\beta 1$ in co-cultured HSCs. Western blot analysis showed that the protein expression levels of $\alpha-S M A, \operatorname{Col} I$, and $T G F \beta 1$ in the HSC/x were also significantly higher than those in the corresponding control groups (Figure 5D,E; $\mathrm{P}<0.05$ ). Thus, expression of the $H B V X$ gene in HL-7702 cells promoted mRNA and protein expression of $\alpha-S M A, C o l$, and TGF 1 in co-cultured HSCs.

\section{DISCUSSION}

HBV infection is associated closely with the development of liver fibrosis and HCC. Currently available evidence supports that HBx activity promotes the procession of HBVlinked HCC through a series of complex molecular mechanisms. However, the roles of HBx in the development of HBV-associated fibrosis remain unclear. Recently, Liu and Bai both reported that HBV affected the proliferation of HSCs in vitro (Liu et al., 2009; Bai et al., 2012). According to these studies, the PDGF-B/PDGFR- $\beta$ signaling pathway and Col I may play important roles in this process (Liu et al., 2009; Bai et al., 2012). Additionally, Guo, Martín-Vílchez both found that HBx protein affected the activity of HSCs in the in vitro coculture systems and revealed that TGF $\beta 1$ may be involved in this process (Martín-Vílchez et al., 2008; Guo et al., 2009). However, the exact mechanisms of HBx-leading fibrosis remain largely debated.

A

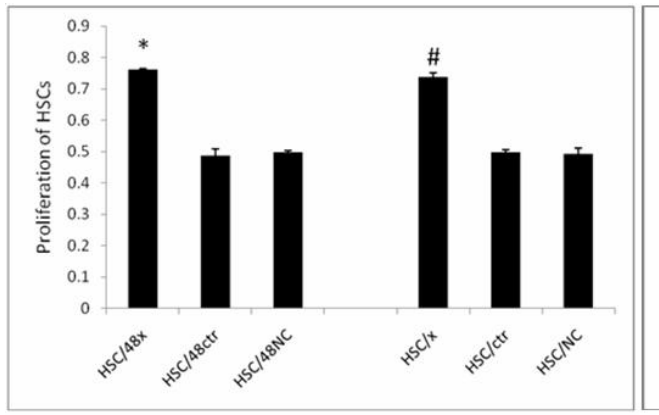

B

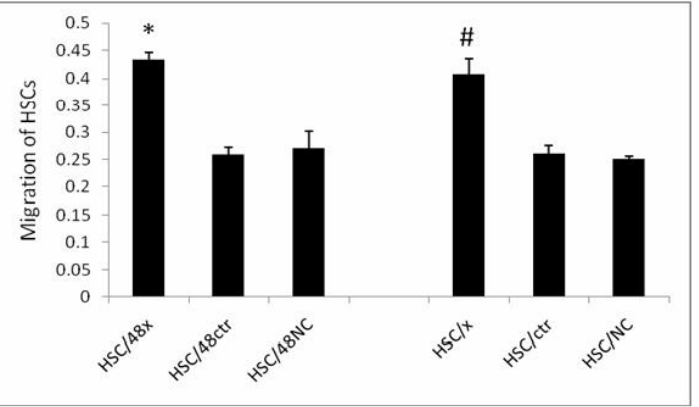

Figure 4. Proliferation and migration of co-cultured hepatic stellate cells (HSCs). A. Proliferation levels of HSCs cocultured with different group of live cells. The proliferations of co-cultured HSCs were detected by CCK8 methods. Data are reported as means \pm SD and analyzed with the $t$-test by the SPSS 17 software. The proliferation levels of HSC/48x, HSC/48ctr, HSC/48NC, HSC/x, HSC/ctr, and HSC/NC are shown as follows, respectively: 0.7617 $\pm 0.0032,0.4883 \pm 0.0190,0.4973 \pm 0.0055,0.7377 \pm 0.0142,0.4970 \pm 0.0085,0.4913 \pm 0.0186(* \mathrm{P}<0.05 v s$ HSC/48ctr, ${ }^{*} \mathrm{P}<0.05$ vs HSC/48NC, ${ }^{\#} \mathrm{P}<0.05$ vs HSC/ctr, ${ }^{*} \mathrm{P}<0.05$ vs $\left.\mathrm{HSC} / \mathrm{NC}\right)$. The results revealed that HSCs cocultured with $\mathrm{HBx}$-expressing live cells have a significantly higher proliferation level than the corresponding control groups. In other words, the expression of HBx promoted the proliferation of HSCs. B. Migration levels of HSCs cocultured with different group of live cells. Data are reported as means $\pm \mathrm{SD}$ and analyzed with the $t$-test by the SPSS 17 software. The migration levels of HSC/48x, HSC/48ctr, HSC/48NC, HSC/x, HSC/ctr, and HSC/NC are shown as follows, respectively: $0.4330 \pm 0.0131,0.2583 \pm 0.0140,0.2703 \pm 0.0319,0.4077 \pm 0.0273,0.2603 \pm 0.0159,0.2500$ $\pm 0.0061\left({ }^{*} \mathrm{P}<0.05\right.$ vs HSC/48ctr, ${ }^{*} \mathrm{P}<0.05$ vs $\mathrm{HSC} / 48 \mathrm{NC}$, ${ }^{*} \mathrm{P}<0.05$ vs $\mathrm{HSC} / \mathrm{ctr},{ }^{*} \mathrm{P}<0.05$ vs $\left.\mathrm{HSC} / \mathrm{NC}\right)$. The results revealed that HSCs co-cultured with $\mathrm{HBx}$-expressing live cells have a significantly higher migration level than the corresponding control groups. That was to say, the expression of HBx promoted the migration of HSCs. 


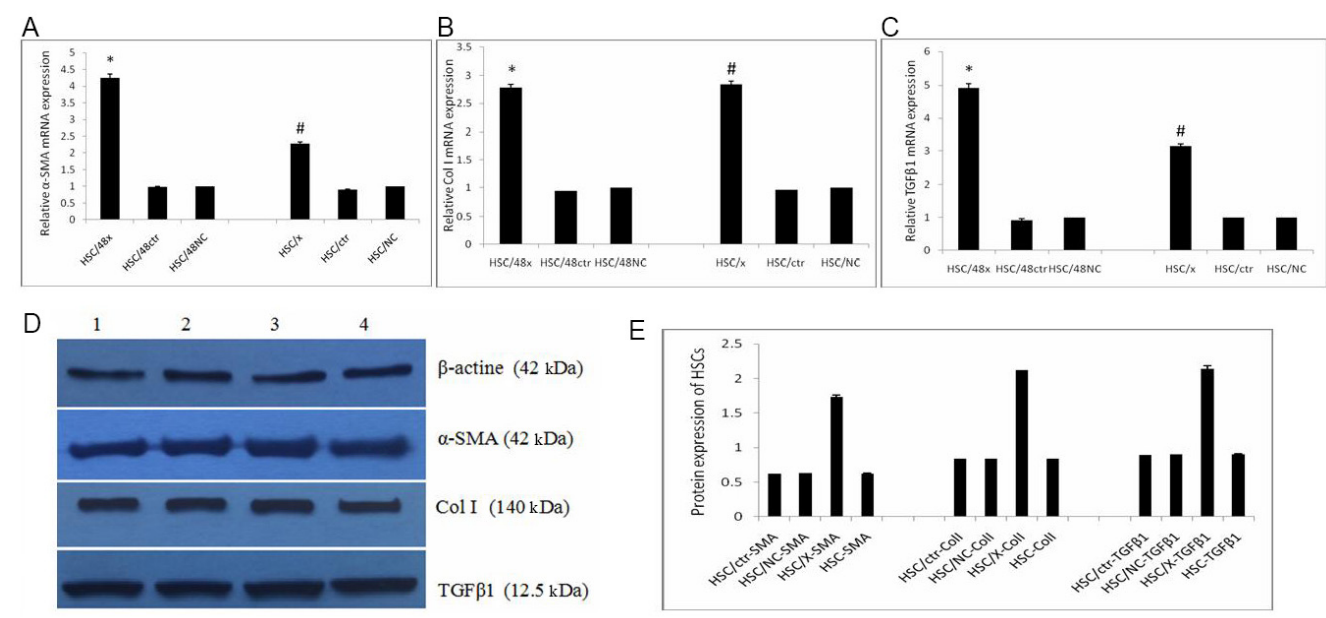

Figure 5. Expression of $\alpha-S M A, C o l$, and TGF 1 in co-cultured hepatic stellate cells (HSCs). A.-C. Relative $\alpha-S M A$, Col I, and TGF 1 mRNA expression levels of HSCs co-cultured with different group of live cells. $\mathrm{HSC} / 48 \mathrm{NC}$ and $\mathrm{HSC} / \mathrm{NC}$ were used as references. Data are reported as means $\pm \mathrm{SD}$ and analyzed with the $t$-test by the SPSS 17 software. The relative $\alpha$-SMA mRNA expression levels of HSC/48x, HSC/48ctr, HSC/x, and HSC/ ctr are shown as follows: $4.2488 \pm 0.1180,0.9774 \pm 0.0280,2.2715 \pm 0.0592,0.9076 \pm 0.0109(* \mathrm{P}<0.05 v s$ $\mathrm{HSC} / 48 \mathrm{ctr},{ }^{*} \mathrm{P}<0.05$ vs HSC/48NC, ${ }^{\#} \mathrm{P}<0.05$ vs HSC/ctr, ${ }^{\#} \mathrm{P}<0.05$ vs HSC/NC). The relative Col I mRNA expression levels of HSC/48x, HSC/48ctr, HSC/x, and HSC/ctr are shown as follows: $2.7898 \pm 0.0509,0.9505 \pm$ $0.0076,2.8484 \pm 0.0525,0.9615 \pm 0.0038\left(* \mathrm{P}<0.05\right.$ vs $\mathrm{HSC} / 48 \mathrm{ctr}, * \mathrm{P}<0.05$ vs $\mathrm{HSC} / 48 \mathrm{NC},{ }^{*} \mathrm{P}<0.05$ vs $\mathrm{HSC} /$ ctr, ${ }^{\mathrm{P}}<0.05$ vs $\left.\mathrm{HSC} / \mathrm{NC}\right)$. The relative TGF $1 \mathrm{mRNA}$ expression levels of HSC/48x, HSC/48ctr, HSC/x, and HSC/ctr are shown as follows: $4.9145 \pm 0.1365,0.9186 \pm 0.0369,3.1461 \pm 0.0705,1.0046 \pm 0.0040(* \mathrm{P}<0.05 v s$ $\mathrm{HSC} / 48 \mathrm{ctr},{ }^{*} \mathrm{P}<0.05$ vs $\mathrm{HSC} / 48 \mathrm{NC},{ }^{*} \mathrm{P}<0.05$ vs HSC/ctr, ${ }^{*} \mathrm{P}<0.05$ s $\left.\mathrm{HSC} / \mathrm{NC}\right)$. The results revealed that $\alpha-S M A$, Col I, and TGFBI mRNA expression levels in HSCs co-cultured with HBx-expressing live cells were significantly higher than those of the corresponding control groups. That was to say, HBx upregulated mRNA expression of $\alpha-S M A, C o l I$, and TGF $\beta$ in HSCs. D. Protein expressions of $\alpha-S M A, C o l I, T G F \beta 1$, and $\beta$-actine in different HSCs. Western blot analysis revealed that different protein expression levels of these four genes in $\mathrm{HSC} / \mathrm{x}$ and control groups. Lane $1=\mathrm{HSC} / \mathrm{ctr}$; lane $2=\mathrm{HSC} / \mathrm{NC}$; lane $3=\mathrm{HSC} / \mathrm{x}$; lane $4=\mathrm{HSC}$ s without co-culture. E. $\alpha$-SMA, Col $\mathrm{I}$ and TGF $\beta 1$ protein expression levels in four groups of HSCs. The protein expression levels of $\alpha$-SMA in HSC/ $\mathrm{ctr}, \mathrm{HSC} / \mathrm{NC}, \mathrm{HSC} / \mathrm{x}$, and HSC are shown as follows: $0.6201 \pm 0.0059,0.6297 \pm 0.0050,1.7298 \pm 0.0347,0.6222$ \pm 0.0063 . Col I protein expression levels in $\mathrm{HSC} / \mathrm{ctr}, \mathrm{HSC} / \mathrm{NC}, \mathrm{HSC} / \mathrm{x}, \mathrm{HSC}$ are shown as follows: $0.8385 \pm$ $0.0014,0.8407 \pm 0.0011,2.1185 \pm 0.0064,0.8392 \pm 0.0015$. TGF $\beta 1$ protein expression levels in HSC/ctr, HSC/NC, $\mathrm{HSC} / \mathrm{x}$, HSC are shown as follows: $0.8897 \pm 0.0060,0.8988 \pm 0.0022,2.1399 \pm 0.0409,0.9045 \pm 0.0049$. There were significant increase of $\alpha$-SMA, Col I and TGF $\beta 1$ protein expression levels in HSCs/x vs HSC/ctr, HSC/NC and HSC $(\mathrm{P}<0.05)$. It means that HBx upregulated $\alpha$-SMA, Col I and TGF $\beta 1$ protein expression levels in HSCs.

To examine the relationship between HBx and liver fibrosis, HL-7702 cells carrying the $H B V X$ gene were co-cultured with HSCs, and then the proliferation and migration of HSCs were detected to determine the effects of HBx on the activity of HSCs. In this in vitro experiment, HL-7702, a normal human live cell line, was co-cultured with HSCs in non-contact transwell co-culture systems. This experimental design is similar to the in vivo environment, and may help to explain the impact of hepatitis B infection on HSCs. Our data revealed that expression of $\mathrm{HBx}$ indeed promoted the proliferation and migration of HSCs.

The activities of HSCs are tightly linked with the progression of liver fibrosis. When HSCs are activated, they show an increased capacity for proliferation, mobility, contractility, and synthesis of collagen and other components of the extracellular matrix (ECM) (Pinzani 
et al., 1998; Pinzani and Marra, 2001; Brandão et al., 2006). Excessive deposition of ECM is a characteristic of fibrogenesis, which effectively amplifies the fibrogenic response (Hui and Friedman, 2003; Parsons et al., 2007). Thus, increasing the proliferation and migration of HSCs indicate that HSCs are activated. In other words, expression of HBx activated HSCs and promoted the formation and development of liver fibrosis.

In addition, expression of $\alpha-S M A$ is also a significant sign of HSC activation (Brandão et al., 2006). Excessive synthesis of ECM components leads to increased expression of $\alpha-S M A$ as well as changes in the expression of L-type voltage-operated $\mathrm{Ca}^{2+}$ channels, which are known to mediate $\mathrm{Ca}^{2+}$ influx and regulate cellular contraction (Gasull et al., 2001; Ahmad and Ahmad, 2012). In our study, HSCs co-cultured with HBx-expressing liver cells showed increased mRNA and protein expression of $\alpha-S M A$ compared to those cells co-cultured with live cells without expressing HBx. Thus, HBx promoted the expression of $\alpha-S M A$ in HSCs and induced activation of HSCs, which is responsible for the development of hepatic fibrosis.

When HSCs are activated, excessive ECM products, particularly Col I, are produced and secreted (Pinzani and Marra, 2001; Ahmad and Ahmad, 2012). Thus, increased expression of $\mathrm{Col} I$ is an indicator of HSC activation. In this experiment, $\mathrm{HBx}$ indeed promoted the expression of Col I, which further confirmed that HSCs had been activated. Expression of the $H B V X$ gene in HL-7702 activate the co-cultured HSCs, including the increased proliferation and migration of HSCs, the upregulation of $\alpha-S M A$, resulting an increased plateau level of $\mathrm{Col}$ $I$ and leading to the development of liver fibrosis.

The precise mechanisms responsible for the development of liver fibrosis remain unclear, but $T G F \beta$ is thought to participate in this pathway (Pinzani and Marra, 2001; Parsons et al., 2007). TGF $\beta 1$ is synthesized and secreted in a latent, biologically inactive form that can bind to the type II TGF- $\beta$ receptor (T $\beta$ RII) and lead to the phosphorylation and activation of the type I TGF- $\beta$ receptor (T $\beta R I)$. This activated T $\beta$ RI kinase phosphorylates Smad 2 or Smad3, which subsequently form a complex with Smad4 and migrate to the nucleus to regulate expression of target genes, including collagens (Bauer and Schuppan, 2001; Zong et al., 2012). In the process of hepatic fibrosis, TGF $\beta$ is the main mediator of fibrogenesis, which can promote activation of HSCs and induce sustained production of ECM components (Friedman, 2000; Pinzani and Marra, 2001; Bataller and Brenner, 2005; Moreira, 2007; Hayashi and Sakai, 2012). Our study confirmed that HBx protein upregulated the mRNA and protein expression of TGF 1 in HSCs, leading to activation of HSCs and increased expression of Col I (Kisseleva and Brenner, 2007).

In summary, this study revealed that the expression of HBx activated HSCs by upregulating TGF 1 . Notably, HL-7702 cells and HSCs were co-cultured in non-contact transwell systems to simulate the in vivo environment. Thus, $\mathrm{HBx}$ protein plays roles via the paracrine pathway (Martín-Vílchez et al., 2008). Whether our conclusions apply to the in vivo environment requires further analysis.

\section{ACKNOWLEDGMENTS}

Research was supported by a grant from the Science and Technology Talent Project of Fujian (\#2008F3043); the Foundation from Department of Health of Fujian for Young Scholars (\#XH200801); the Foundation from Ministry of Education for Doctors in Collages (\#20093518110003); and the Foundation from Fujian Health Department for Clinical Key 
Specialist. We thank Nan-Hong Tang and Xiao-Qian Wang for providing technical support.

\section{REFERENCES}

Ahmad A and Ahmad R (2012). Understanding the mechanism of hepatic fibrosis and potential therapeutic approaches. Saudi J. Gastroenterol. 18: 155-167.

Bai Q, An J, Wu X, You H, et al. (2012). HBV promotes the proliferation of hepatic stellate cells via the PDGF-B/ PDGFR- $\beta$ signaling pathway in vitro. Int. J. Mol. Med. 30: 1443-1450.

Bataller R and Brenner DA (2005). Liver fibrosis. J. Clin. Invest. 115: 209-218.

Bauer M and Schuppan D (2001). TGFbeta1 in liver fibrosis: time to change paradigms? FEBS Lett. 502: 1-3.

Brandão DF, Ramalho LN, Ramalho FS, Zucoloto S, et al. (2006). Liver cirrhosis and hepatic stellate cells. Acta Cir. Bras. 21 (Suppl 1): 54-57.

Chen HY, Tang NH, Li XJ, Zhang SJ, et al. (2004). Transfection and expression of hepatitis B virus $\mathrm{x}$ gene and its effect on apoptosis in HL-7702 cells. World J. Gastroenterol. 10: 959-964.

Chen HY, Tang NH, Lin N, Chen ZX, et al. (2008). Hepatitis B virus X protein induces apoptosis and cell cycle deregulation through interfering with DNA repair and checkpoint responses. Hepatol. Res. 38: 174-182.

Dewantoro O, Gani RA and Akbar N (2006). Hepatocarcinogenesis in viral hepatitis B infection: the role of HBx and p53. Acta Med. Indones. 38: 154-159.

Friedman SL (2000). Molecular regulation of hepatic fibrosis, an integrated cellular response to tissue injury. J. Biol. Chem. 275: 2247-2250.

Gasull X, Bataller R, Gines P, Sancho-Bru P, et al. (2001). Human myofibroblastic hepatic stellate cells express $\mathrm{Ca}^{2+}-$ activated $\mathrm{K}^{+}$channels that modulate the effects of endothelin-1 and nitric oxide. J. Hepatol. 35: 739-748.

Gearhart TL and Bouchard MJ (2011). The hepatitis B virus HBx protein modulates cell cycle regulatory proteins in cultured primary human hepatocytes. Virus Res. 155: 363-367.

Guo GH, Tan DM, Zhu PA and Liu F (2009). Hepatitis B virus X protein promotes proliferation and upregulates TGFbeta1 and CTGF in human hepatic stellate cell line, LX-2. Hepatobiliary. Pancreat. Dis. Int. 8: 59-64.

Ha HL and Yu DY (2010). HBx-induced reactive oxygen species activates hepatocellular carcinogenesis via dysregulation of PTEN/Akt pathway. World J. Gastroenterol. 16: 4932-4937.

Hayashi H and Sakai T (2012). Biological significance of local TGF- $\beta$ activation in liver diseases. Front Physiol. 3: 12.

Hsieh A, Kim HS, Lim SO, Yu DY, et al. (2011). Hepatitis B viral X protein interacts with tumor suppressor adenomatous polyposis coli to activate Wnt/beta-catenin signaling. Cancer Lett. 300: 162-172.

Hui AY and Friedman SL (2003). Molecular basis of hepatic fibrosis. Expert. Rev. Mol. Med. 5: 1-23.

Kim K, Kim KH and Cheong J (2010). Hepatitis B virus X protein impairs hepatic insulin signaling through degradation of IRS1 and induction of SOCS3. PLoS One 5: e8649.

Kisseleva T and Brenner DA (2007). Role of hepatic stellate cells in fibrogenesis and the reversal of fibrosis. $J$. Gastroenterol. Hepatol. 22 (Suppl 1): S73-S78.

Knoll S, Furst K, Thomas S, Villanueva BS, et al. (2011). Dissection of cell context-dependent interactions between HBx and p53 family members in regulation of apoptosis: a role for HBV-induced HCC. Cell Cycle 10: 3554-3565.

Liu X, Zhu ST, You H, Cong M, et al. (2009). Hepatitis B virus infects hepatic stellate cells and affects their proliferation and expression of collagen type I. Chin. Med. J. 122: 1455-1461.

Martín-Lluesma S, Schaeffer C, Robert EI, van Breugel PC, et al. (2008). Hepatitis B virus X protein affects S phase progression leading to chromosome segregation defects by binding to damaged DNA binding protein 1. Hepatology 48: 1467-1476.

Martín-Vilchez S, Sanz-Cameno P, Rodriguez-Munoz Y, Majano PL, et al. (2008). The hepatitis B virus X protein induces paracrine activation of human hepatic stellate cells. Hepatology 47: 1872-1883.

Matsuda Y and Ichida T (2009). Impact of hepatitis B virus X protein on the DNA damage response during hepatocarcinogenesis. Med. Mol. Morphol. 42: 138-142.

Moreira RK (2007). Hepatic stellate cells and liver fibrosis. Arch. Pathol. Lab. Med. 131: 1728-1734.

Nebbia G, Peppa D and Maini MK (2012). Hepatitis B infection: current concepts and future challenges. QJM 105: 109113.

Parsons CJ, Takashima M and Rippe RA (2007). Molecular mechanisms of hepatic fibrogenesis. J. Gastroenterol. Hepatol. 22 (Suppl 1): S79-S84.

Pinzani M and Marra F (2001). Cytokine receptors and signaling in hepatic stellate cells. Semin. Liver Dis. 21: 397-416.

Pinzani M, Marra F and Carloni V (1998). Signal transduction in hepatic stellate cells. Liver 18: 2-13.

Qadri I, Fatima K and AbdeL-Hafiz H (2011). Hepatitis B virus X protein impedes the DNA repair via its association with 
transcription factor, TFIIH. BMC. Microbiol. 11: 48.

Yip WK, Cheng AS, Zhu R, Lung RW, et al. (2011). Carboxyl-terminal truncated HBx regulates a distinct microRNA transcription program in hepatocellular carcinoma development. PLoS One 6: e22888.

Zong L, Qu Y, Xu MY, Dong YW, et al. (2012). 18a-glycyrrhetinic acid down-regulates expression of type I and III collagen via TGF-Beta1/Smad signaling pathway in human and rat hepatic stellate cells. Int. J. Med. Sci. 9: 370-379. 